\title{
POLLEN ACCUMULATION RATES AT ROGERS LAKE, CONNECTICUT, DURING LATE- AND POSTGLACIAL TIME
}

\author{
MARGARET B. DAVIS
}

Department of Zoology and Great Lakes Research Division, University of Michigan, Ann Arbor, Mich. (U.S.A.)

(Received August 29, 1966)

\section{SUMMARY}

Pollen accumulation rates have been estimated by dividing the pollen number per unit volume in $1 \mathrm{ml}$ samples from a core from Rogers Lake, Connecticut, by the number of years represented by each sample. The latter variable was estimated from 24 radiocarbon-dated levels within the core. The result shows that total pollen deposition rose steeply from $1,000 / \mathrm{cm}^{2} /$ year, 14,000 years ago to $10,000 / \mathrm{cm}^{2}$ / year in later Late Glacial time, reaching a maximum of $40,000 / \mathrm{cm}^{2} /$ year, 9,000 years ago when the Pine Pollen Zone (B) was deposited. Subsequently the deposition rate fell to $20,000-25,000 / \mathrm{cm}^{2} /$ year, remaining stable at this level for the last 8,000 years.

The pollen-percentage stratigraphy at Rogers Lake is similar to that at other sites in the vicinity. The changes in pollen percentages in sediments less than 8,000 years old directly reflect changes in deposition rates for these types, since the pollen total was almost constant. A rise in the numbers of Carya pollen grains took place about 5,000 years ago, and minimum rates for Tsugapollen deposition occurred between 1,500 and 4,000 years ago. These changes have been considered evidence for a xerothermic interval, but this event may be represented instead by the maximum in percentages and increase in deposition rates for Ambrosia pollen that occurred between 5,000 and 8,000 years ago.

In sediments older than 8,000 years, the changes in pollen percentages are quite different from the changes in rates of pollen deposition of individual types. The pollen-accumulation-rate diagram shows that few pollen grains from trees were being deposited 12,000 years ago. Spruce pollen increased at that time, reaching a maximum 10,000 years ago, when an open spruce woodland may have grown in the region. Pine pollen began to increase 12,000 years ago, reaching maximum rates 9,000 years ago 18 times higher than the later Postglacial rate. Oak pollen increased in numbers 12,000 years ago and held steady throughout the remainder of Late Glacial time, increasing rapidly by a factor of 30 during Early Postglacial time. 
On this 50th anniversary of Von Post's presentation of the first pollen diagrams, it is appropriate to renew discussion of the ideas he proposed at that time. Von Post's interpretations of the first pollen diagrams were based largely on the changes in pollen percentages that occurred from one stratigraphical level to another. While he was aware of constraint on pollen frequencies at each level, and thus on their changes between levels, imposed by the interdependence of values within a percentage system, he felt it important that the values obtained were at least independent of the types of peat in which the pollen was enclosed. This was not true of alternative forms in which the data might have been presented, such as absolute numbers of grains per unit volume or weight of peat. Absolute numbers would depend strongly upon the different accumulation rates of the different kinds of peat; thus counts from different peat types, or from different deposits, could not be compared meaningfully with one another. Von Post suggested, however, that there might be an advantage in working with absolute pollen frequency, if the relative accumulation rates of peat types could be estimated. If characteristic relative rates were found, these could be used to correct pollen numbers observed in different samples. In this manner it might be possible to compare rates of pollen accumulation independently from the accumulation rates of the enclosing peat (VoN PosT, 1916).

The discovery, in recent years, of radiometric methods for determining ages of sediments makes it possible to estimate absolute rates of sediment accumulation. Thus the method of absolute pollen analysis suggested by Von Post can at last be applied, and its results compared with conventional pollen analyses. To this end a series of radiocarbon dates have been obtained from different levels within an $11 \mathrm{~m}$ core of gyttja and silt from Rogers Lake, in southern Connecticut, in a study of deposition rates of microfossils in collaboration with E. S. Deevey Jr., of Yale University. These data are used to estimate the number of years represented by a unit of thickness of sediment at each level within the profile. The numbers of pollen grains of each type in samples of measured volume are then divided by the estimated number of years necessary for their accumulation. This yields an estimate of the number of grains of each type deposited on the sediment surface per year. The accumulation rate for pollen types estimated in this way is a variable independent both of changes involving other pollen types, and of changes in the rate of accumulation of the sediment matrix.

The present paper presents a summary of the results of applying this method to the entire core of Late Glacial and Postglacial sediment from Rogers Lake. The results are compared with the traditional percentage diagram, a comparison that has special meaning in this case because the lake lies within the type area for New England Postglacial pollen zones as established by DEEVEY (1939). Previously, the radiocarbon ages of several of the pollen zones were known 
only by inference or from correlation with the European pollen sequence. The new pollen diagram also shows new and potentially important stratigraphical features, as these are some of the first detailed analyses of Postglacial lake sediments that have been published from this region.

Preliminary results from the Late Glacial portion of the Rogers Lake core have already been published (DAVIS and DEEVEY, 1964), as have the results of application of the same methods to animal microfossils preserved in the Late Glacial sediment (DeEveY, 1964). Livingstone (1957) had previously done a similar paleolimnological study using laminations in sediment to estimate accumulation rates, while methods similar to those employed in the present investigation have recently been applied to pollen analyses by WHITEHEAD (1967) and TsuKaDA (1966).

\section{METHODS}

The Rogers Lake core, $11 \mathrm{~m}$ long and $5 \mathrm{~cm}$ in diameter, was collected with a Livingstone corer by Deevey and myself in 1960. Milliliter samples were removed from the extruded core for pollen, microfossil and chemical analyses. The remainder was divided into segments, $5-20 \mathrm{~cm}$ in length, which were used for radiocarbon dating by Dr. Minze Stuiver, Director, Yale Radiocarbon Laboratory. Results from eight samples from the lowest $2 \mathrm{~m}$ have already been published (Stuiver et al., 1963). Dr. Stuiver has kindly made available to me unpublished results from 16 additional samples, spaced at approximately $60 \mathrm{~cm}$ intervals throughout the upper $9 \mathrm{~m}$ of core. The radiocarbon ages of all the samples have been corrected by +730 years, an amount equal to the average apparent age of three surface samples (M. Stuiver, personal communication, 1966). (Note change from the previous correction of +770 years based on 2 surface samples.) The results from surface samples indicate a source of ${ }^{14} \mathrm{C}$-deficient carbon in the lake, presumably groundwater; the correction assumes that this source contributed carbon in the same proportion throughout Late- and Postglacial time (Stuiver et al., 1963; Davis and DeEvey, 1964).

Small samples were assayed for pollen content by the aliquot slide method described elsewhere (DAvIs, 1965a, 1966). From 200 to 1,000 grains were counted in each sample; the counts were used both for calculation of pollen percentages and estimation of absolute pollen frequencies.

\section{RESULTS AND DISCUSSION}

\section{Sedimentation rate}

The radiocarbon ages of the 24 samples were plotted against their depths below the mud surface to show the relationship between depth and age of the 
sediment. A smooth curve was then fitted to the points, in order that the equation of the line could be used to predict age from depth, and in order that its slope could be used to estimate sedimentation rates. A curve was fitted to the points by eye, curving through the points up to $7 \mathrm{~m}$ depth and continuing straight from this level to the surface. A second-degree equation was found that approximated the lower portion of the line, and a first-degree equation that approximated the upper portion. These are shown in Fig.1. More recently additional radiocarbon age determinations have been made (M. Stuiver, personal communication, 1966). The dates from these samples, when plotted against depth, fall close to the line given here, implying that additional data will not bring about any major change in interpretation of sedimentation rates.

The curves fitted to the data shown in Fig. 1 indicate that 14,000 years ago the net rate of sediment accumulation after compaction and diagenesis was about 26.9 years $/ \mathrm{cm}$ thickness $(0.037 \mathrm{~cm} /$ year). (This is similar to the previous estimate of $0.036 \mathrm{~cm} /$ year, based on a straight regression line fitted to the lowest 8 samples (DAvis and Deevey, 1964).) The rate of sedimentation gradually increased, until at about 6,000 years B.P. it gave way to a constant rate of 8.6 years $/ \mathrm{cm}(0.116 \mathrm{~cm} /$ year $)$ which continued to the present.

\section{Total pollen deposition}

The total pollen numbers per unit volume sediment, shown in the left-hand part of Fig.2, were similar in samples from adjacent levels. This consistency indicates that there were few very short-term changes in the rate of accumulation of the sediment matrix, and that the rate of pollen input to the sediment is a variable showing long-term changes lasting one or more millenia, rather than short-term changes lasting decades or centuries.

The oldest sediments, deposited before 12,000 years B.P., contain fewer than 20,000 pollen grains $/ \mathrm{ml}$. The number increased in the younger sediments, reaching maximum values in sediments deposited 9,000 years ago. Above this level, the number decreased, until a more or less stable concentration of $200,000 / \mathrm{ml}$ was reached at about 5,000 years B.P.

By correcting these values for the rates of accumulation of the sediment matrix characteristic for each level within the profile, we can now distinguish between those changes in pollen number that are the result of changes in sedimentation rate, and those that reflect changes in the pollen input to the sediment.

The sedimentation rate, in terms of years/cm accumulation, is shown plotted against estimated age in the middle column of Fig.2. The pollen number has been divided by this variable, yielding the estimated rates of pollen accumulation shown in the right-hand column. The results show that very few pollen grains, less than $1,000 / \mathrm{cm}^{2} /$ year, were being deposited before about 12,000 years ago. At this time the rate of pollen accumulation began to increase, reaching 


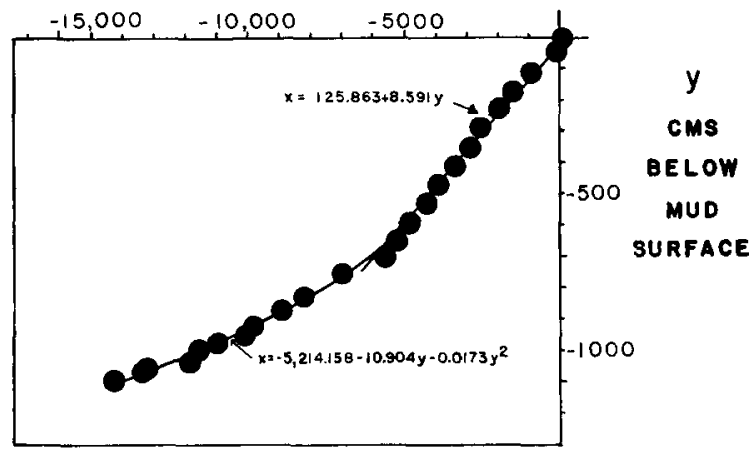

Fig.1. Relationship between radiocarbon age and depth below mud surface of sediment from the Rogers Lake core. The equations describe smooth lines fit by eye to the 24 radiocarbon-dated levels.

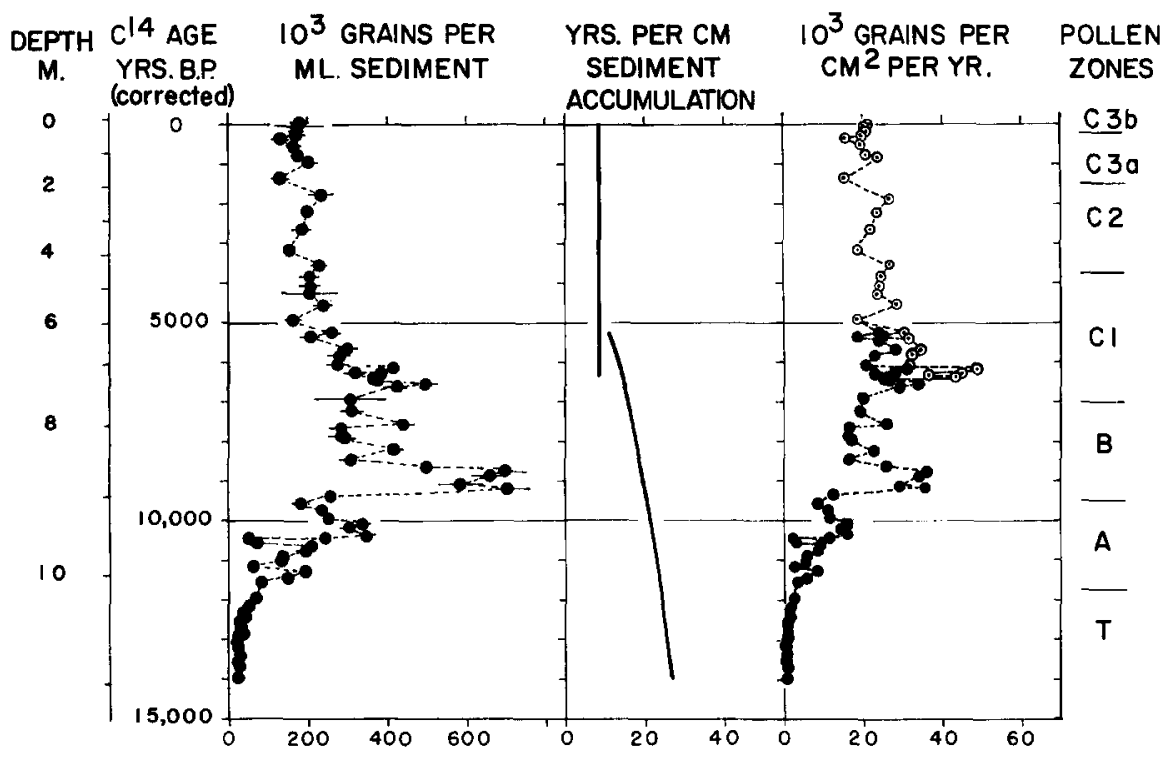

Fig.2. To the left, estimated total pollen from terrestrial plants per ml sediment, with $95 \%$ confidence intervals surrounding the estimates, is plotted against the estimated age of the samples. In the center column the estimated numbers of years represented by a $\mathrm{cm}$ thickness sediment (the derivatives of the curves shown in Fig.1) are plotted against the estimated age of the sediment. To the right are estimates of the rates of total pollen accumulation at various times in the past, derived by dividing the number of grains per $\mathrm{cm}^{3}$ by the estimated number of years represented by the sample. Black dots represent estimates based on the derivative of the second-degree polynomial fitted to the older radiocarbon-dated samples; gray dots represent estimates based on the derivative of the straight line fitted to the younger samples. 
15,000 grains $/ \mathrm{cm}^{2} /$ year 10,000 years ago, and rising steeply to a maximum rate of 35,000 grains $/ \mathrm{cm}^{2} /$ year 9000 years ago. The rate of pollen accumulation then decreased again to $20,000-25,000$ grains $/ \mathrm{cm}^{2} /$ year, a rate that has remained more or less stable for the last 8,000 years.

\section{Pollen stratigraphy}

The quantities of individual pollen types can be expressed either as percentages of the pollen total, or as numbers deposited $/ \mathrm{cm}^{2} /$ year. In sediments younger than 8,000 years, the total pollen deposition rate was nearly constant; consequently almost all the changes in percentage values for individual pollen types (Fig.3) directly reflect changes in the deposition rates for these types (Fig.4). But in the older sediments, the total pollen deposition rate varied with time by a factor of 40 . This variation has resulted in considerable distortion in the record of pollen deposition provided by changes in the pollen percentages.

The pollen percentages are shown plotted against the estimated age of the sediments in Fig.3; the diagram is divided into pollen zones in the traditional manner. Non-arboreal pollen types were dominant before 12,000 years B.P. (zones T and A-1), with Pinus the most abundant tree pollen type. Subsequently Pinus, Picea, and Quercus-pollen percentages increased (A-2-3). Ten thousand years ago, Quercus-pollen percentages decreased to a minimum, and pollen grains of Pinus, Picea and Alnus increased in frequency (A-4). 9,000 B.P., Pinus became the dominant pollen type. An upper boundary for the Pine Pollen Zone (B) has been drawn at 7,000 years B.P. where pine-pollen percentages fall below $10 \%$.

Comparison with Fig.4 shows that these changes in pollen percentages are misleading as indicators of changes in pollen deposition, and thus give a misleading impression of changes in the vegetation. Very few pollen grains of any kind were deposited before 12,000 years B.P. (Fig.4). Despite their relatively high percentages (totalling almost $40 \%$ ), tree pollen grains were few in number. Those few that arrived at the site were probably windblown from far-distant forests. 12,000 years B.P., the numbers of all tree pollen types increased, while the numbers of herb pollen grains remained constant or increased slightly. Macrofossils (at other sites) indicate that trees grew in the region at this time, although there may also have been extensive areas of tundra-like vegetation persisting. Deposition rates for conifer pollen continued to increase between 12,000 and 10,000 years B.P., implying a gradual increase in the numbers of pollen grains produced by the vegetation as coniferous trees increased in frequency. I believe that the increase may represent the gradual development of an open spruce (Picea) woodland in southern New England, an interpretation based on the resemblance of pollen percentages in zone A-4 to those in surface samples from open spruce woodland at latitude $53^{\circ} \mathrm{N}$ in northern Quebec (DAvIS, 1967). During this time the numbers of pollen grains from $Q u e r c u s$ and other temperate deciduous trees remained more or 


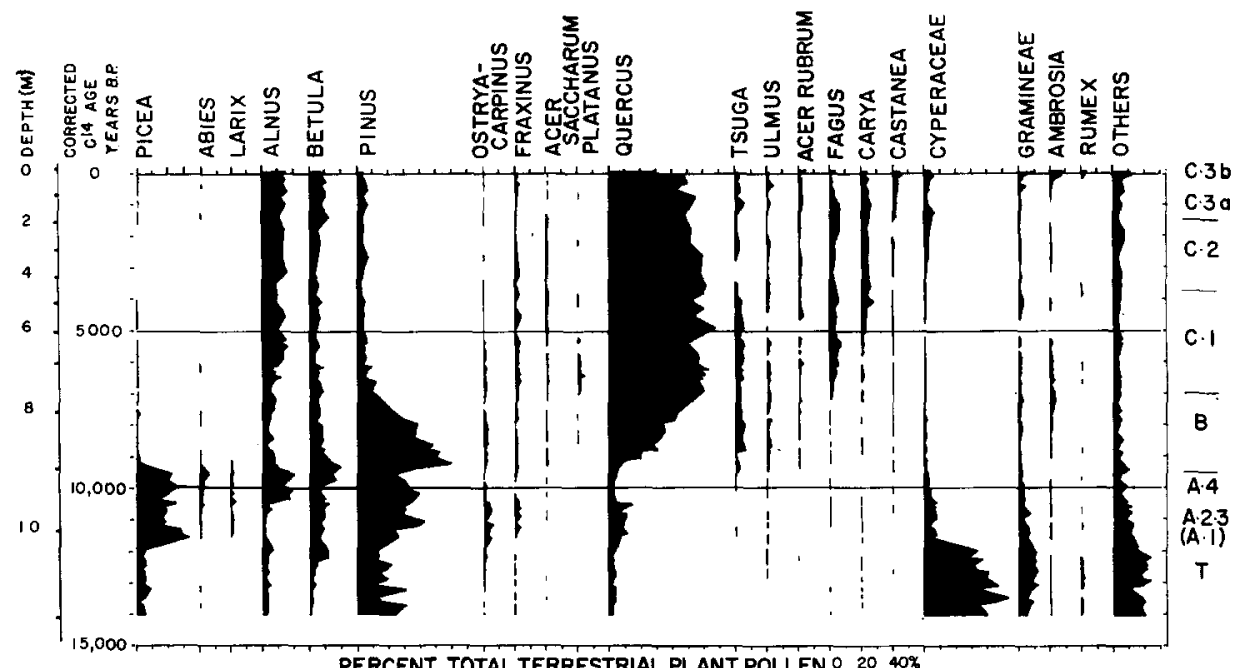

PERCENT TOTAL TERRESTRIAL PLANT POLLEN O $20 \quad 40 \%$

Fig.3. Pollen percentages of selected pollen types in sediments from the Rogers Lake core, plotted against the estimated age of the sediment. Percentages are calculated as percent total pollen from terrestrial plants.

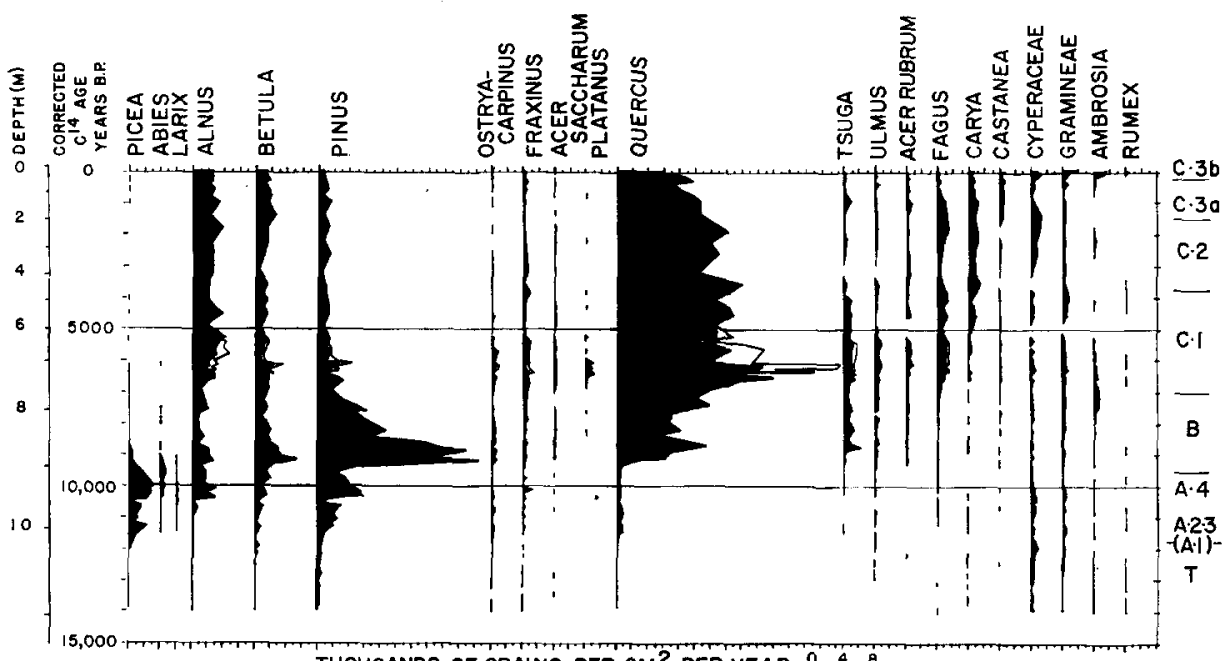

THOUSANDS OF GRAINS PER CM ${ }^{2}$ PER YEAR 04.9

Fig.4. Accumulation rates for selected pollen types at Rogers Lake, calculated by dividing the estimated numbers per sample by the estimated number of years necessary for their accumulation. The accumulation rates are all shown at the same scale, plotted against the radiocarbon age of the sediment. Two rates, indicated by the shaded and unshaded silhouettes, are shown for each type in samples from the zone of overlap of the two equations used to estimate the number of years per $\mathrm{cm}$ sediment thickness. 
less constant; there is no indication in the deposition-rate diagram for a maximum at 11,000 years and a minimum at 10,000 years such as is found in the percentage diagram. The changes in Quercus-pollen percentages in Fig.3 are, therefore, merely a reflection of increasing deposition rates for coniferous-tree pollen 10,000 years ago, and not, as had been suggested previously, of a climatic oscillation correlated with the Allerød (DAvIS and DEEVEY, 1964).

9,000 years B.P. ago, deposition rates for Betula, Pinus, Quercus and other tree-pollen types increased sharply, with Pinus pollen reaching maximum deposition rates 18 times higher than its deposition rate during later Postglacial time. The high percentage of pine pollen in zone B had conveyed a correct impression of very abundant pine at this time relative to its frequency during later Postglacial time (DeEvey, 1939; many later authors). My previous assertion that the high pine-pollen percentage of zone B resulted alone from low pollen productivity by the rest of the vegetation (DAvIS, 1963) is clearly incorrect as applied to Rogers Lake.

In the younger sediments the three pollen zones of Deevey (1939) can be recognized both in the percentage diagram (Fig.3) and the deposition rate diagram (Fig.4). The sequence from Quercus-Tsuga (C-1), to Quercus-Carya (C-2) to Quercus-Castanea (C-3) can be seen clearly. There may be some argument, however, concerning the precise levels at which zone boundaries should be placed. As the minimum in the percentages of Tsuga pollen is the most consistent feature of zone C-2 to be seen over a wide geographical region (DAvIS, 1965b), I have used this feature as the basis for drawing the zone boundaries at Rogers Lake. I have also subdivided C-3, with pollen zone C-3b, which is characterized by rising values for Ambrosia pollen, presumably recording forest clearance by European settlers (McANDREWs, 1966).

Several new features of the Postglacial pollen sequence can be recognized at Rogers Lake. First, the diagram shows a resemblance to the new detailed analyses from Silver Lake, Ohio (OGDEN, 1966). As at Silver Lake, there is a minimum in Fagus-pollen percentages about 3,000 years ago, and a maximum of Ambrosia pollen between about 5,000 and 8,000 years ago. The Ambrosia maximum (of both percentages and numbers at Rogers Lake) is of particular interest, since similarly high percentages of herb pollen are found at equivalent stratigraphical levels in diagrams from forested regions in northeast Minnesota (FrIES, 1962) and in Wisconsin (WEST, 1961). Ambrosia pollen occurs in relatively high percentages $(5-40 \%)$ in surface samples from the deciduous-forest region of the northeastern and northcentral U.S.A.; the plant seems to have increased as the result of disturbance and the creation of open habitats through forest clearance by European settlers. In presettlement sediments from forested regions of Minnesota, it occurs in frequencies of 1-2\% (FRIES, 1962; MCANDrEws, 1966), while farther from the modern prairie, in southern Michigan (M. B. Davis, unpublished) or Ohio (OGDEN, 1966) it is very rare $(<1 \%)$ in presettlement 
samples. The maximum of Ambrosia pollen between 5,000 and 8,000 years ago could, therefore, represent either disturbance of the forests, or local conditions similar in some way to those in modern forests near the prairie margin. Another possibility is that the pollen was windblown from midwestern prairies; this possibility seems ruled out by the absence of similarly high percentages of $\mathrm{Am}$ brosia pollen at stratigraphically equivalent levels in lake sediment farther north, in Vermont (DAvis, 1965b). Since the recent studies in Minnesota have so convincingly demonstrated that the prairie-forest boundary moved eastward between about 5,000 and 8,000 years B.P. (Wright et al., 1963; CUSHING, 1965; MC ANDREWs, 1966) it seems reasonable to conclude that the climatic event that caused this change is also recorded by the Ambrosia-pollen maximum in sediments of the same age at Silver Lake, Ohio, and Rogers Lake, Connecticut.

A more detailed vegetational interpretation of the pollen evidence will indicate whether the Ambrosia maximum represents a "xerothermic interval" in the northeast, or whether the changes in pollen percentages in the younger pollen zone, C-2, record an event of this kind, as has been thought previously (DeEvey, 1939; DeEvey and Flint, 1957; Odgen, 1966). Interpretation of pollen zones A-4 and B has been facilitated by comparisons with modern pollen assemblages from northern Quebec, on the one hand, and the northern Great Lakes region, on the other (DAvIS, 1967). I feel confident that much of the Postglacial pollen sequence, including the Ambrosia-pollen maximum and the overlying C-2 zone, can eventually be interpreted by this method. A more continental climate in the past might have brought about the development of forests in southern Connecticut similar to those that occurred before forest clearance in the Midwest and Great Lakes region. It is in these regions that we should look for modern or presettlement analogs to the pollen assemblages deposited at Rogers Lake between 9,000 and 1,500 years ago. Only the youngest pollen zone, C-3, with its increased percentages of Castanea pollen, resembles surface samples from Rogers Lake and its vicinity. This implies that forests similar to those that occurred in southern Connecticut at the time European colonists arrived had developed only within the past 1,500 years.

\section{CONCLUSIONS}

The results from Rogers Lake indicate that estimation of sedimentation rates by means of series of radiocarbon dates is feasible; pollen analysis in cores of lake sediment can, therefore, be put on an absolute basis. But one may still question whether such an expensive and laborious method is worthwhile. At times when the deposition rate for total pollen is relatively uniform, as during almost the entire Postglacial interval at Rogers Lake, the percentage diagram conveys almost all the information about changes in individual types contained 
in the deposition-rate diagram. More could be learned, of course, if deposition rates could be related to numbers of trees, in which case the deposition-rate diagram would yield a population count for the various tree genera. It seems unlikely, however, that any such relationship exists, as the number of pollen grains entering a lake per unit area probably varies with lake size (TAUBER, 1965). It may even be questioned whether the deposition rate at the point where the core was taken is proportional to the total pollen input to the lake, rather than dependent upon local, and possibly varying, conditions of sedimentation.

These questions may prove less serious than might be supposed if additional absolute diagrams show that changes in deposition rates are stratigraphically consistent. If so, it will be worthwhile to obtain at least a few absolute diagrams from each vegetation region, if only to indicate the times when the total pollen deposition rate was constant and when for this reason changes in pollen percentages reflect changes in pollen input to the lake. Evidence from Rogers Lake shows that the total number of pollen grains produced by the vegetation is more stable (FAGERLIND, 1952) than I had imagined; the views I expressed earlier (DAvis, 1963) were an exaggeration of the true situation. Certainly one of the implications of my previous paper, that the Pine Pollen Zone (B) could not be interpreted as a time of abundant pine, has now been shown to be incorrect. The same conclusion regarding zone $B$ has been drawn from comparisons of the pollen percentages in zone B-1 with surface samples, which show that they are similar to modern pollen assemblages from the mixed coniferous-deciduous region of eastern Ontario north of the Great Lakes, a region where pine, although not the dominant genus, occurs frequently (DAVIs, 1967).

Present experience indicates that absolute diagrams will be most valuable for the interpretation of Late Glacial pollen sequences, many of which record vegetation that changed drastically in pollen productivity as tundra was replaced by park tundra and woodland, and woodland was replaced by forest. As a result, the changes in pollen percentages from one level to another are distorted and cannot indicate directly the direction of vegetation change. In some cases, too, the Late Glacial vegetation may have been quite different from any vegetation existing today; comparisons cannot be made with modern analogs. With these two methods of interpretation made difficult or impossible, the absolute pollen diagram becomes a practical method of investigation.

\section{ACKNOWLEDGEMENTS}

This paper is Contribution No.60 from the Great Lakes Research Division, the University of Michigan. The research was generously supported by the National Science Foundation, through Grant G-19335 to Yale University in 1960-1961 and through Grants G-17830 and GB-2377 to the University of 
Michigan in 1961-1966. I gratefully acknowledge the collaboration of Edward S. Deevey Jr., who originally suggested that sedimentation rates could be estimated from radiocarbon dates with sufficient accuracy for application to pollen analyses. I express special thanks to Dr. Minze Stuiver for permitting me to make use of unpublished radiocarbon age determinations. Radiocarbon age determinations were done at the Yale Radiocarbon Laboratory with the support of N.S.F. Grant GP-4879.

\section{REFERENCES}

Cushing, E. J., 1965. Problems in the Quaternary phytogeography of the Great Lakes region. In: H. E. WRIGHT JR. and D. G. FReY (Editors), The Quaternary of the United States. Princeton Univ. Press, Princeton, N, J., pp.403-416.

Davis, M. B., 1963. On the theory of pollen analysis. Am. J. Sci., 261: 897-912.

DAvIs, M. B., 1965a. A method for determination of absolute pollen frequency. In: B. KUMmeL and D. RAuP (Editors), Handbook of Paleontological Techniques. Freeman, San Francisco, Calif., pp.674-686.

Davis, M. B., 1965b. Phytogeography and palynology of northeastern United States. In: H. E. WRIGHT JR. and D. G. FreY (Editors), The Quaternary of the United States. Princeton Univ. Press, Princeton, N. J., pp.377-401.

DAvis, M. B., 1966. Determination of absolute pollen frequency. Ecology, 47: 310-311.

Davis, M. B., 1967. Late-Glacial climate in northern United States: a comparison of New England and the Great Lakes region. In: E. J. CusHING and H. E. Wright JR. (Editors), Quaternary Paleoecology. Yale Univ. Press, New Haven, Conn., in press.

Davis, M. B. and DeEvy JR., E. S., 1964. Pollen accumulation rates: estimates from Late Glacial sediment of Rogers Lake. Science, 145: 1293-1295.

Deevey JR., E. S., 1939. Studies on Connecticut lake sediments, 1. A Postglacial climatic chronology for southern New England. Am. J. Sci., 241: 717-752.

DeEveY JR., E. S., 1964. Preliminary account of fossilization of zooplankton in Rogers Lake. Proc. Intern. Assoc. Theoret. Appl. Limnol., 15: 981-992.

Deevey JR., E. S. and Flint, R. F., 1957. Postglacial hypsithermal interval. Science, 125: 182-184.

FAGERLIND, F., 1952. On the real signification of pollen diagrams. Botan. Notiser, 1952: 185-224.

Fries, M., 1962. Pollen profiles of Late Pleistocene and Recent sediments from Weber Lake, Minnesota. Ecology, 43: 295-308.

Livingstone, D. A., 1957. On the sigmoid growth phase in the history of Linsley Pond. Am. J. Sci, 255: 364-373.

MCANDREws, J. H., 1966. Postglacial history of prairie, savanna, and forest in northwestern Minnesota. Torrey Botan. Club Mem., 22: 1-72.

OGDEN III, J. G., 1966. Forest history of Ohio, 1. Radiocarbon dates and pollen stratigraphy of Silver Lake, Logan Country, Ohio. Ohio J. Sci., 66: 387-400.

Stuiver, M., Deevey JR., E. S. and Rouse, I., 1963. Yale natural radiocarbon measurements, VIII. Radiocarbon, 5: 312-341.

TAUBER, H., 1965. Differential pollen dispersion and the interpretation of pollen diagrams. Danmarks Geol. Undersegelse, II, 89: 1-69.

Tsukada, M., 1966. Late Postglacial pollen diagram from Lake Nojiri. Botan. Mag. (Tokyo), 79: $179-184$.

VoN Post, L., 1916. Om skogsträdpollen i sydsvenska torfmosselagerföljder. Geol. Fören. Stockholm Förh., 38: 384-390; diskussionsinlägg, pp.392-393.

WEST, R. G., 1961. Late Glacial and Postglacial vegetation history in Wisconsin, particularly changes associated with the Valders readvance. Am. J. Sci., 259: 766-783. 
WHITEHEAD, D. R., 1967. Full-glacial vegetation and climate in southeastern United States. In: E. J. Cushing and H. E. WRIGHT JR. (Editors), Quaternary Paleoecology. Yale Univ. Press, New Haven, Conn., in press.

Wright JR., H. E., Winter, T. C. and Patten, H. L., 1963. Two pollen diagrams from southeastern Minnesota: problems in the regional Late Glacial and Postglacial vegetational history. Bull. Geol. Soc. Am., 74: 1371-1396. 